\title{
Overdose experiences among injection drug users in Bangkok, Thailand
}

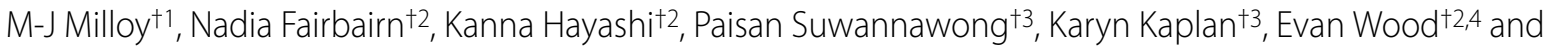
Thomas Kerr*+2,4

\begin{abstract}
Background: Although previous studies have identified high levels of drug-related harm in Thailand, little is known about illicit drug overdose experiences among Thai drug users. We sought to investigate non-fatal overdose experiences and responses to overdose among a community-recruited sample of injection drug users (IDU) in Bangkok, Thailand.

Methods: Data for these analyses came from IDU participating in the Mit Sampan Community Research Project. The primary outcome of interest was a self-reported history of non-fatal overdose. We calculated the prevalence of past overdose and estimated its relationship with individual, drug-using, social, and structural factors using multivariate logistic regression. We also assessed the prevalence of ever witnessing an overdose and patterns of response to overdose.

Results: These analyses included 252 individuals; their median age was 36.5 years (IQR: 29.0 - 44.0) and 66 (26.2\%) were female. A history of non-fatal overdose was reported by 75 (29.8\%) participants. In a multivariate model, reporting a history of overdose was independently associated with a history of incarceration (Adjusted Odds Ratio [AOR] = 3.83, 95\% Confidence Interval [Cl]: $1.52-9.65, p=0.004)$ and reporting use of drugs in combination $(\mathrm{AOR}=2.48,95 \% \mathrm{Cl}: 1.16$ - 5.33, $p=0.019)$. A majority (67.9\%) reported a history of witnessing an overdose; most reported responding to the most recent overdose using first aid (79.5\%).

Conclusions: Experiencing and witnessing an overdose were common in this sample of Thai IDU. These findings support the need for increased provision of evidence-based responses to overdose including peer-based overdose interventions.
\end{abstract}

\section{Background}

Accidental illicit drug-related overdose is a leading cause of preventable morbidity and mortality. In many settings, fatal overdose is the primary contributor to highly elevated mortality rates among injection drug users (IDU) $[1,2]$. According to several studies of communityrecruited IDU, non-fatal overdose is common and associated with factors including having a prior history of overdose, recent incarceration and higher-intensity forms of drug use, such as poly-drug use [3-6]. Several interventions to lower the incidence or reduce the damaging sequelae of overdose events have been implemented,

\footnotetext{
* Correspondence: uhri-tk@cfenet.ubc.ca

2 British Columbia Centre for Excellence in HIV/AIDS, St. Paul's Hospital, $667-$

1081 Burrard Street, Vancouver, British Columbia, V6Z 1Y6, Canada

+ Contributed equally

Full list of author information is available at the end of the article
}

including treatment for drug use [7], drug substitution therapy [8], supervised injection facilities [9] and peerdriven responses, such as naloxone distribution [10].

Despite reports of injection drug use from all major regions of the world $[11,12]$, the phenomenon of accidental drug overdose has not been well described outside of Western settings. In northern Vietnam, over $80 \%$ of outof-treatment male opiate injectors reported a history of overdose in a cross-sectional survey [13]. Overdose in the previous 12 months was common among 731 IDU in Sichuan province, China, and associated with daily heroin use and an injection career of at least seven years in duration [14].

In Thailand, some aspects of drug-related harm, including high levels of incarceration [15], persecution by police [16] and infection with HIV $[17,18]$ hepatitis C [19] 
and other pathogens [20] have been identified among the estimated 20,000 - 160,000 IDU in the country $[11,12]$. However, we are unaware of any study that analyses the phenomenon of overdose among Thai drug users. Thus, we sought to estimate the prevalence and correlates of non-fatal overdose, as well as investigate patterns of response to overdose in a community-recruited sample of active IDU in Bangkok, Thailand.

\section{Methods}

Data for these analyses was obtained from the Mit Sampan Community Research Project (MSCRP), a collaborative research effort involving the Mit Sampan Harm Reduction Center (Bangkok, Thailand), the Thai AIDS Treatment Action Group (Bangkok, Thailand), Chulalongkorn University (Bangkok, Thailand) and the British Columbia Centre for Excellence in HIV/AIDS (Vancouver, Canada). In 2008, the research partners designed and undertook a cross-sectional epidemiological study of IDU recruited through peer-based outreach and word-ofmouth. Invited participants were asked to attend the Mit Sampan Harm Reduction Center to be included in the study. All participants provided informed consent and completed an interviewer-administered questionnaire. The survey instrument elicited demographic data, information about past and current drug use, HIV risk behaviour, overdose experiences, interactions with the criminal justice system including police forces and incarceration, and experience with health care. Upon completion of the questionnaire participants were provided a stipend of 250 Thai baht. The study was approved by the research ethics boards at the University of British Columbia and Chulalongkorn University.

For these analyses, the primary endpoint of interest was reporting a history of non-fatal overdose by answering "Yes" to the question: "Have you ever overdosed by accident (i.e., a period of loss of consciousness or breathing?)" In follow-up questions, individuals reporting a history of non-fatal overdose were also asked the type of drug or drugs they were using at the time of their last overdose, if they were helped, and by who, during their last overdose.

As a first step, we investigated the characteristics of individuals with a history of overdose. Explanatory variables included: Age; gender (male vs. female); education level (<prathom suksa [elementary-level] vs. $\geq$ prathom suksa); reporting any income from illegal sources (yes vs. no); participation in the sex trade (yes vs. no); history of heroin injection (yes vs. no); history of Midazolam (a benzodiazepine) injection (yes vs. no); history of yaba (methamphetamine and caffeine) injection (yes vs. no); history of ice (methamphetamine) injection (yes vs. no); history of using drugs in combination (yes vs. no); history of methadone injection (yes vs. no); ever using an unsterile syringe (yes vs. no); ever lending syringes (yes vs. no); ever incarcerated (yes vs. no); ever on methadone maintenance therapy (MMT) (yes vs. no); and ever in forced drug treatment (yes vs. no). Pearson's $\mathrm{X}^{2}$-test and Fisher's exact test were used to determine bivariate relationships.

Next, we used an a priori-defined statistical protocol based on examination of the Akaike Information Criterion (AIC) and $p$-values to construct an explanatory multivariate logistic regression model. First, we constructed a full model including all variables analysed in bivariate analyses. After noting the AIC of the model, we removed the variable with the largest $p$-value and built a reduced model. We continued this iterative process until no variables remained for inclusion. We selected the multivariate model with the lowest AIC score.

In a secondary analysis, all participants were asked if they had ever witnessed an overdose. Those with a history of witnessing overdose were asked about their response to the most recently witnessed overdose. Finally, all participants were asked if they believed they had enough information to prevent and manage overdose and what steps they believe should be taken to effectively manage overdose.

\section{Results}

Two-hundred fifty-two individuals were recruited and included in these analyses, of whom 66 (26.1\%) were women. The median age at time of interview was 36.5 years (IQR: 29.0 - 44.0 years.) In total, 75 participants (29.8\%) reported a history of non-fatal overdose. When asked about the type and routes of administration of all drugs consumed prior to their last overdose, almost all (70, 93.3\%) reported injection heroin, followed by injection Midazolam (24, 32.0\%), non-injection heroin (11, $14.7 \%)$ and non-injection midazolam (4, 5.3\%). No other response (including injection and non-injection yaba, non-injection ecstasy, injection and non-injection methadone, injection and non-injection benzodiazepine and injection and non-injection alcohol) exceeded three $(4.0 \%)$ reports.

Of the 75 participants with a history of overdose, 59 (78.7\%) reported being helped by another individual during their last overdose. Most reported being assisted by a friend $(46,78.0 \%)$, relative $(11,18.6 \%)$ or sex partner $(3$, $5.1 \%)$. Of all individuals reporting an overdose, only 28 (33.5\%) reported being seen by a healthcare professional.

Results of the univariate analyses of factors associated with reporting a history of non-fatal overdose are presented in Table 1. As shown, the outcome was associated at the $p<0.05$ level with: reporting a history of incarceration (Odds Ratio [OR] $=4.40,95 \%$ Confidence Interval [CI]: 1.80 - 10.79); a history of using drugs in combination $(\mathrm{OR}=3.05,95 \% \mathrm{CI}: 1.53-6.07)$; and a history of injecting Midazolam ( $\mathrm{OR}=2.20,95 \% \mathrm{CI}: 1.67$ - 4.12). A history of injecting heroin was significantly associated with report- 
Table 1: Univariate analyses of factors associated with reporting a history of non-fatal overdose among IDU in MSHRC cohort ( $\mathrm{n}=\mathbf{2 5 2}$ individuals).

\begin{tabular}{|c|c|c|c|c|c|}
\hline \multirow[t]{2}{*}{ Characteristic } & \multicolumn{2}{|c|}{ History of overdose $\mathbf{n}(\%)$} & \multirow[t]{2}{*}{$\mathrm{OR}^{1}$} & \multirow[t]{2}{*}{$95 \% \mathrm{Cl}^{2}$} & \multirow[t]{2}{*}{ p-va } \\
\hline & No: 177 (70.2) & Yes: 75 (29.8) & & & \\
\hline \multicolumn{6}{|l|}{ AGE } \\
\hline Median (IQR) & $37.0(29.5-44.5)$ & $35.0(28.0-42.0)$ & 0.99 & $0.97-1.03$ & 0.843 \\
\hline \multicolumn{6}{|l|}{ GENDER } \\
\hline Male & $130(73.4)$ & $56(74.7)$ & & & \\
\hline Female & $47(26.6)$ & $19(25.3)$ & 0.93 & $0.51-1.74$ & 0.877 \\
\hline \multicolumn{6}{|l|}{ EDUCATION } \\
\hline$\geq$ Secondary & $110(62.1)$ & $50(66.7)$ & 1.00 & & \\
\hline$<$ Secondary & $37(37.9)$ & $25(33.4)$ & 0.82 & $0.47-1.45$ & 0.568 \\
\hline \multicolumn{6}{|l|}{ SEX TRADE } \\
\hline No & $167(94.4)$ & $71(94.7)$ & 1.00 & & \\
\hline Yes & $10(5.6)$ & $4(5.3)$ & 0.94 & $0.29-3.10$ & 0.841 \\
\hline \multicolumn{6}{|c|}{ EVER INJECT HEROIN } \\
\hline No & $18(10.1)$ & $0(0.0)$ & & & \\
\hline Yes & $159(89.9)$ & $75(100.0$ & & & 0.002 \\
\hline \multicolumn{6}{|l|}{ EVER INJECT YABA } \\
\hline No & $66(37.3)$ & $25(33.3)$ & 1.00 & & \\
\hline Yes & $111(62.7)$ & $50(66.7)$ & 1.19 & $0.67-2.10$ & 0.570 \\
\hline \multicolumn{6}{|c|}{ EVER INJECT MIDAZOLAM } \\
\hline No & $66(37.3)$ & $16(21.3)$ & 1.00 & & \\
\hline Yes & $111(62.7)$ & $59(78.7)$ & 2.20 & $1.67-4.12$ & 0.018 \\
\hline \multicolumn{6}{|c|}{ EVER INJECT BENZODIAZEPINES } \\
\hline No & $174(98.3)$ & $73(97.3)$ & 1.00 & & \\
\hline
\end{tabular}


Table 1: Univariate analyses of factors associated with reporting a history of non-fatal overdose among IDU in MSHRC cohort ( $n=252$ individuals). (Continued)

\begin{tabular}{|c|c|c|c|c|c|}
\hline Yes & $3(1.7)$ & $2(2.7)$ & 1.59 & $0.26-9.71$ & 0.636 \\
\hline \multicolumn{6}{|c|}{ EVER INJECT METHADONE } \\
\hline No & $150(84.7)$ & $63(84.0)$ & 1.00 & & \\
\hline Yes & $27(15.3)$ & $12(16.0)$ & 1.06 & $0.50-2.22$ & 0.851 \\
\hline \multicolumn{6}{|c|}{ EVER USE DRUGS IN COMBINATION } \\
\hline No & $65(36.7)$ & $12(16.0)$ & 1.00 & & \\
\hline Yes & $112(63.3)$ & $63(84.0)$ & 3.05 & $1.53-6.07$ & $<0.001$ \\
\hline \multicolumn{6}{|c|}{ EVER INCARCERATED } \\
\hline No & $49(27.7)$ & $6(8.0)$ & 1.00 & & \\
\hline Yes & $128(72.3)$ & $69(92.0)$ & 4.40 & $1.80-10.79$ & $<0.001$ \\
\hline \multicolumn{6}{|c|}{ EVER ON MMT } \\
\hline No & $102(57.7)$ & $39(52.0)$ & 1.00 & & \\
\hline Yes & $75(42.3)$ & $36(48.0)$ & 1.26 & $0.73-2.16$ & 0.488 \\
\hline \multicolumn{6}{|c|}{ EVER IN FORCED DRUG TREATMENT } \\
\hline No & $127(71.8)$ & $45(60.0)$ & 1.00 & & \\
\hline Yes & $50(28.2)$ & $30(40.0)$ & 1.69 & $0.96-2.82$ & 0.076 \\
\hline
\end{tabular}

1. Odds Ratio; $2.95 \%$ Confidence Interval

ing ever experiencing a non-fatal overdose $(p=0.002)$; however, as all individuals with a history of overdose also reported a history of heroin injection, an Odds Ratio could not be calculated and that explanatory factor was removed from further consideration. The final multivariate model, presented in Table 2, included two factors independently associated with the outcome: Ever using drugs in combination (Adjusted Odds Ratio [AOR] = 2.48, 95\% CI: 1.16 - 5.33) and reporting a history of incarceration $(\mathrm{AOR}=3.83,95 \% \mathrm{CI}: 1.52$ - 9.65).

Experience witnessing an overdose was reported by 171 (67.9\%) participants. When asked their response to the last overdose witnessed, most $(136,79.5 \%)$ reported performing first aid; 78 (45.6\%) took the overdose sufferer to a hospital; 4 (2.3\%) took them to the Mit Sampan Harm
Reduction Centre; 1 (0.6\%) contacted the police. Twelve individuals $(7.0 \%)$ reported they did nothing in response.

Approximately half of the participants reported they believed they had enough information to prevent (139, $55.2 \%)$ and manage $(128,50.8 \%)$ an overdose. When asked how to manage an overdose, responses were: perform first aid (115, 45.6\%); inject salt water $(109,43.2 \%)$; perform CPR (90, 35.7\%); slap (105, 41.7\%); administer naloxone $(16,6.3 \%)$; or take to a hospital $(74,29.4 \%)$.

\section{Discussion}

In these analyses, we found a history of non-fatal overdose was common among Thai IDU, with more than onequarter of the sample (29.8\%) reporting a previous overdose event. The predominant drug implicated in over- 
Table 2: Multivariate logistic regression analysis of factors associated with reporting a history of non-fatal overdose in MSHRC cohort ( $n=252$ individuals).

\begin{tabular}{lccc}
\hline Characteristic & AOR ${ }^{1}$ & $\mathbf{9 5 \% ~ C l} \mathbf{2}^{\mathbf{2}}$ & $\mathbf{p}$-value \\
\hline $\begin{array}{l}\text { Ever injected Midazolam (Yes } \\
\text { vs. no) }\end{array}$ & 1.38 & $0.68-2.81$ & 0.379 \\
\hline $\begin{array}{l}\text { Ever used in combination (Yes } \\
\text { vs. no) }\end{array}$ & 2.48 & $1.16-5.33$ & 0.020 \\
\hline $\begin{array}{l}\text { Ever incarcerated (Yes vs. no) } \\
\text { Ever in forced treatment (Yes }\end{array}$ & 3.83 & $1.52-9.65$ & 0.004 \\
vs. no) & 1.25 & $0.69-2.28$ & 0.457 \\
\hline
\end{tabular}

1. Adjusted Odds Ratio; 2. 95\% Confidence Interval

dose events was heroin, with the majority of individuals reporting injecting heroin before their last overdose and every individual with a history of overdose also reporting a history of heroin use. In a multivariate model, a history of overdose was linked to poly-drug use and incarceration. Most of the participants also reported experience witnessing an overdose (67.9\%) and the most common responses included performing first aid and taking the victim to a hospital. When asked how to manage an overdose, the most common responses included performing first aid or artificial respiration and injecting salt water.

The level of non-fatal overdose observed in this sample is on the lower end of the range of estimates calculated in similar studies of community-based IDU in Baltimore, Maryland (24.7\%) [21]; London, England (37.8\%) [22] and San Francisco, California (47.9\%) [23]. We are unable to determine if this comparatively lower level is the result of a lower incidence of overdose among Thai IDU or a greater risk of death at each overdose event. Several points of evidence support a contribution from the latter effect, including the high prevalence of witnessing overdoses; the pervasive level of misperceptions concerning how to manage an overdose; the high prevalence of overdose as the reported cause of death among Thai IDU in two HIV vaccine preparatory studies [24,25]; and the ongoing violent crackdown by Thai police against drug users, a phenomenon linked to a greater risk of overdose mortality in other settings [26-28].

Our findings identify the need for enhanced education for Thai IDU to prevent and manage overdoses. Specifically, approximately half of respondents indicated they did not have the information required to prevent and manage overdoses. This lack of knowledge was reflected in the substantial proportion of participants reporting inappropriate responses, including injecting the sufferer with salt water. Given that witnessing an overdose was common in this setting and fatal overdoses typically take hours to develop [29,30], the need to improve peer responses is clear. Inappropriate or suboptimal responses by IDU to overdose are not uncommon and have been reported from a number of settings $[26,29,31]$. However, overdose management education has been shown to be effective at training IDU to respond appropriately to overdose [26,32].

These findings also support the distribution of naloxone to drug users. Naloxone, an opiate antagonist, is the standard treatment used by healthcare professionals in resuscitation efforts following opioid overdose. Programs to train IDU in overdose response alongside distribution of naloxone would likely benefit Thai IDU, given that opiates were the most common class of drugs reported by this sample prior to their last overdose. Additionally, given pervasive anti-drug user stigma [33,34] and the ongoing violent campaign by police [35], many IDU may be unwilling to seek professional health care in the event of an overdose. Evaluations of analagous interventions in Chicago [36], New York City [10] and San Francisco [37] have observed positive impacts, including hundreds of successful peer opioid overdose resuscitations. Currently, naloxone is only available to IDU in Thailand at the MSHRC.

In the multivariate model, a history of incarceration was independently associated with ever overdosing. This is in line with previous analyses that have identified a high risk of overdose, including fatal overdose, associated with incarceration, especially in the first weeks following release from detention $[38,39]$. In the Thai context, previous studies have described the links between exposure to correctional environments and an elevated risk of HIV infection among IDU $[40,41]$. Our findings add evidence supporting the need for an expansion of harm reduction opportunities in Thai correctional settings, such as substitution therapies, shown effective at reducing HIV risk 
behaviours [42] and improving outcomes post-release [43].

While the implementation of peer-based interventions might lower the incidence and severity of overdose events among Thai IDU, our findings also have implications for other social- and structural-level policies. In particular, our findings are another example of how the reliance on enforcement-based strategies to respond to illicit drug use can produce further drug-related harms [44,45]. Just as some observers have identified deaths resulting from the Thai government's crackdown on drug users [35], our findings describe how criminal justice interventions can increase the risks associated with overdose events. We echo other authors who have credited the country's successful efforts to reduce the incidence of sexually-transmitted HIV infections to the government's adoption of evidence-based policies $[41,46]$ and urge a similar pragmatic initiative to replace dominant enforcement- and suppression-based policies with harm reduction programmes.

Our study has limitations. First, cross-sectional analyses are unable to determine the temporal relationship between outcome and exposure. Second, although our measures are based on self-reports from IDU, we do not believe participants would have been more or less likely to report a history of overdose based on the covariates we examined. Finally, our sample of IDU was not recruited at random and thus may not necessarily generalize to other samples of IDU in Thailand or other settings.

\section{Conclusions}

We observed that non-fatal overdose events were common in this sample of Thai IDU. In a multivariate analysis, reporting a history of non-fatal overdose was independently associated with ever being incarcerated and ever using drugs in combination. A majority of participants reported witnessing overdoses as well as needing more information to respond appropriately. Our findings support the need to expand appropriate harm reduction strategies for drug users in Thailand, such as peer-based overdose management including naloxone distribution, and further highlight the need to balance the current emphasis on enforcement-based responses to illicit drug use with health-focused interventions.

\section{Competing interests}

The authors declare that they have no competing interests.

\section{Authors' contributions}

TK, EW, PS and KK conceived and designed the study; KK, PS, NF and KH implemented the study design, including data acquisition; M-JM performed the statistical analysis, wrote the manuscript and coordinated all revisions; all authors revised the manuscript and read and approved the final draft.

\section{Acknowledgements}

We would like to thank the staff and volunteers at the Mitsampan Harm Reduction Center for their support. We also thank Dr. Niyada Kiatying-Angsulee of the
Social Pharmacy Research Unit (SPR), Faculty of Pharmaceutical Sciences, Chulalongkorn University, for her assistance with developing this project. We also thank Deborah Graham and Calvin Lai for their assistance with data management; Prempreeda Pramoj Na Ayutthaya and Donlachai Hawangchu for their assistance with data collection. This work was funded by the Canadian Institutes of Health Research (Grant RAA-79918).

\section{Author Details}

1School of Population and Public Health, University of British Columbia, 5804 Fairview Avenue, Vancouver, British Columbia, V6T 1C3, Canada, ${ }^{2}$ British Columbia Centre for Excellence in HIV/AIDS, St. Paul's Hospital, 667-1081 Burrard Street, Vancouver, British Columbia, V6Z 1Y6, Canada, ${ }^{3}$ Thai AIDS Treatment Action Group, 18/89 Vipawadee Road, soi 40, Chatuchak, Bangkok, Thailand and 4 Department of Medicine, University of British Columbia, Room 10203, 2775 Laurel Street, Vancouver, British Columbia, V5Z 1M9, Canada

Received: 26 October 2009 Accepted: 13 May 2010

Published: 13 May 2010

\section{References}

1. Bargagli AM, Hickman M, Davoli M, Perucci CA, Schifano P, Buster M, Brugal T, Vicente J, Group CE: Drug-related mortality and its impact on adult mortality in eight European countries. European journal of public health 2006, 16:198-202

2. Centers for Disease Control: Unintentional poisoning deaths--United States, 1999-2004. MMWR Morb Mortal Wkly Rep 2007, 56:93-96.

3. Darke S, Hall W: Heroin overdose: research and evidence-based intervention. J Urban Health 2003, 80:189-200

4. Darke S, Williamson A, Ross J, Mills KL, Havard A, Teesson M: Patterns of nonfatal heroin overdose over a 3-year period: findings from the Australian treatment outcome study. Journal of urban health: bulletin of the New York Academy of Medicine 2007, 84:283-291.

5. Kerr T, Fairbairn N, Tyndall M, Marsh D, Li K, Montaner J, Wood E: Predictors of non-fatal overdose among a cohort of polysubstanceusing injection drug users. Drug Alcohol Depend 2007, 87:39-45.

6. Ochoa KC, Davidson PJ, Evans JL, Hahn JA, Page-Shafer K, Moss AR: Heroin overdose among young injection drug users in San Francisco. Drug Alcohol Depend 2005, 80:297-302.

7. Darke S, Williamson A, Ross J, Teesson M: Non-fatal heroin overdose, treatment exposure and client characteristics: findings from the Australian treatment outcome study (ATOS). Drug Alcohol Rev 2005, 24:425-432

8. van Ameijden EJ, Langendam MW, Coutinho RA: Dose-effect relationship between overdose mortality and prescribed methadone dosage in low-threshold maintenance programs. Addict Behav 1999, 24:559-563.

9. Milloy MJ, Kerr T, Tyndall M, Montaner J, Wood E: Estimated drug overdose deaths averted by North America's first medically-supervised safer injection facility. PLOS ONE 2008, 3:e3351.

10. Piper TM, Stancliff S, Rudenstine S, Sherman S, Nandi V, Clear A, Galea S: Evaluation of a naloxone distribution and administration program in New York City. Subst Use Misuse 2008, 43:858-870.

11. Aceijas C, Friedman SR, Cooper HL, Wiessing L, Stimson GV, Hickman M: Estimates of injecting drug users at the national and local level in developing and transitional countries, and gender and age distribution. Sexually transmitted infections 2006, 82(Suppl 3):iii10-17.

12. Aceijas C, Stimson GV, Hickman M, Rhodes T, United Nations Reference Group on HIV/AIDS Prevention and Care among IDU in Developing and Transitional Countries: Global overview of injecting drug use and HIV infection among injecting drug users. AIDS 2004, 18:2295-2303.

13. Bergenstrom A, Quan VM, Van Nam L, McClausland K, Thuoc NP, Celentano D, Go V: A cross-sectional study on prevalence of non-fatal drug overdose and associated risk characteristics among out-oftreatment injecting drug users in North Vietnam. Subst Use Misuse 2008, 43:73-84.

14. Yin L, Qin G, Ruan Y, Qian H, Hao C, Xie L, Chen K, Zhang Y, Xia Y, Wu J, et al: Nonfatal overdose among heroin users in southwestern China. The American journal of drug and alcohol abuse 2007, 33:505-516.

15. Beyrer C, Jittiwutikarn J, Teokul W, Razak MH, Suriyanon V, Srirak N, Vongchuk T, Tovanabutra S, Sripaipan T, Celentano DD: Drug use, 
increasing incarceration rates, and prison-associated HIV risks in Thailand. AIDS and behavior 2003, 7:153-161.

16. Kerr T, Kaplan K, Suwannawong P, Wood E: Health and human rights in the midst of a drug war: the Thai Drug Users' Network. In Public health and human rights: Evidence-based approaches Edited by: Beyrer C, Pizer H. Baltimore, Maryland, United States: Johns Hopkins; 2007.

17. Celentano DD, Hodge MJ, Razak MH, Beyrer C, Kawichai S, Cegielski JP, Nelson KE, Jittiwutikarn J: HIV-1 incidence among opiate users in northern Thailand. Am J Epidemiol 1999, 149:558-564.

18. Latkin CA, Donnell D, Metzger D, Sherman S, Aramrattna A, Davis-Vogel A, Quan VM, Gandham S, Vongchak T, Perdue T, Celentano DD: The efficacy of a network intervention to reduce HIV risk behaviors among drug users and risk partners in Chiang Mai, Thailand and Philadelphia, USA. Soc Sci Med 2008:740-748

19. Jittiwutikarn J, Thongsawat S, Suriyanon V, Maneekarn N, Celentano D, Razak MH, Srirak N, Vongchak T, Kawichai S, Thomas D, et al:: Hepatitis C infection among drug users in northern Thailand. Am J Trop Med Hyg 2006, 74:1111-1116.

20. Celentano DD, Sirirojn B, Sutcliffe CG, Quan VM, Thomson N, Keawvichit R, Wongworapat K, Latkin C, Taechareonkul S, Sherman SG, Aramrattana A: Sexually transmitted infections and sexual and substance use correlates among young adults in Chiang Mai, Thailand. Sex Transm Dis 2008, 35:400-405.

21. Latkin CA, Hua W, Tobin K: Social network correlates of self-reported non-fatal overdose. Drug Alcohol Depend 2004, 73:61-67.

22. Strang J, Powis B, Best D, Vingoe L, Griffiths P, Taylor C, Welch S, Gossop M: Preventing opiate overdose fatalities with take-home naloxone: prelaunch study of possible impact and acceptability. Addiction 1999, 94:199-204

23. Seal KH, Kral AH, Gee L, Moore LD, Bluthenthal RN, Lorvick J, Edlin BR: Predictors and prevention of nonfatal overdose among streetrecruited injection heroin users in the San Francisco Bay Area, 19981999. Am J Public Health 2001, 91:1842-1846.

24. Vanichseni S, Kitayaporn D, Mastro TD, Mock PA, Raktham S, Des Jarlais DC, Sujarita S, Srisuwanvilai LO, Young NL, Wasi C, et al:: Continued high HIV-1 incidence in a vaccine trial preparatory cohort of injection drug users in Bangkok, Thailand. AIDS 2001, 15:397-405.

25. Pitisuttithum P, Gilbert P, Gurwith M, Heyward W, Martin M, van Griensven F, Hu D, Tappero JW, Choopanya K: Randomized, double-blind, placebocontrolled efficacy trial of a bivalent recombinant glycoprotein 120 HIV-1 vaccine among injection drug users in Bangkok, Thailand. J Infect Dis 2006, 194:1661-1671.

26. Pollini RA, McCall L, Mehta SH, Celentano DD, Vlahov D, Strathdee SA: Response to overdose among injection drug users. Am J Prev Med 2006, 31:261-264.

27. Tracy M, Piper TM, Ompad D, Bucciarelli A, Coffin PO, Vlahov D, Galea S: Circumstances of witnessed drug overdose in New York City: implications for intervention. Drug Alcohol Depend 2005, 79:181-190.

28. Seal KH, Downing M, Kral AH, Singleton-Banks S, Hammond JP, Lorvick J, Ciccarone D, Edlin BR: Attitudes about prescribing take-home naloxone to injection drug users for the management of heroin overdose: a survey of street-recruited injectors in the San Francisco Bay Area. J Urban Health 2003, 80:291-301.

29. Davidson PJ, McLean RL, Kral AH, Gleghorn AA, Edlin BR, Moss AR: Fatal heroin-related overdose in San Francisco, 1997-2000: a case for targeted intervention. J Urban Health 2003, 80:261-273.

30. Zador D, Sunjic S, Darke S: Heroin-related deaths in New South Wales, 1992: toxicological findings and circumstances. Med J Aust 1996, 164:204-207.

31. Davidson PJ, Ochoa KC, Hahn JA, Evans JL, Moss AR: Witnessing heroinrelated overdoses: the experiences of young injectors in San Francisco. Addiction 2002, 97:1511-1516.

32. Green TC, Heimer R, Grau LE: Distinguishing signs of opioid overdose and indication for naloxone: an evaluation of six overdose training and naloxone distribution programs in the United States. Addiction 2008, 103:979-989.

33. Chan KY, Stoove MA, Sringernyuang L, Reidpath DD: Stigmatization of AIDS patients: disentangling Thai nursing students' attitudes towards HIV/AIDS, drug use, and commercial sex. AIDS Behav 2008, 12:146-157.

34. Simmonds $L$, Coomber R: Injecting drug users: A stigmatised and stigmatising population. Int J Drug Policy 2007:121-130.
35. Human Rights Watch: Not enough graves: The war on drugs, HIV/AIDS, and violations of human rights. New York City, New York, United States: Human Rights Watch; 2004.

36. Maxwell S, Bigg D, Stanczykiewicz K, Carlberg-Racich S: Prescribing naloxone to actively injecting heroin users: a program to reduce heroin overdose deaths. JAddict Dis 2006, 25:89-96.

37. Seal KH, Thawley R, Gee L, Bamberger J, Kral AH, Ciccarone D, Downing M, Edlin BR: Naloxone distribution and cardiopulmonary resuscitation training for injection drug users to prevent heroin overdose death: a pilot intervention study. J Urban Health 2005, 82:303-311.

38. Binswanger IA, Stern MF, Deyo RA, Heagerty PJ, Cheadle A, Elmore JG, Koepsell TD: Release from prison--a high risk of death for former inmates. NEngl J Med 2007, 356:157-165.

39. Farrell $M$, Marsden J: Acute risk of drug-related death among newly released prisoners in England and Wales. Addiction 2008, 103:251-255.

40. Buavirat A, Page-Shafer K, van Griensven GJ, Mandel JS, Evans J, Chuaratanaphong J, Chiamwongpat S, Sacks R, Moss A: Risk of prevalent HIV infection associated with incarceration among injecting drug users in Bangkok, Thailand: case-control study. BMJ 2003, 326:308.

41. Beyrer C, Jittiwutikarn J, Teokul W, Razak MH, Suriyanon V, Srirak N, Vongchuk T, Tovanabutra S, Sripaipan T, Celentano DD: Drug use, increasing incarceration rates, and prison-associated HIV risks in Thailand. AIDS Behav 2003, 7:153-161.

42. Sorensen $J$, Copeland AL: Drug abuse treatment as an HIV prevention strategy: a review. Drug Alcohol Depend 2000, 59:17-31.

43. Gordon MS, Kinlock TW, Schwartz RP, O'Grady KE: A randomized clinical trial of methadone maintenance for prisoners: findings at 6 months post-release. Addiction 2008, 103:1333-1342

44. Kerr T, Small W, Wood E: The public health and social impacts of drug market enforcement: A review of the evidence. Int J Drug Policy 2005, 16:210-220.

45. Maher L, Dixon D: Policing and public health: Law enforcement and harm minimization in a street-level drug market. British Journal of Criminology 1999, 39:488-512.

46. Celentano DD: HIV prevention among drug users: an international perspective from Thailand. J Urban Health 2003, 80:iii97-105.

doi: 10.1186/1477-7517-7-9

Cite this article as: Milloy et al., Overdose experiences among injection drug users in Bangkok, Thailand Harm Reduction Journal 2010, 7:9

\section{Submit your next manuscript to BioMed Central and take full advantage of:}

- Convenient online submission

- Thorough peer review

- No space constraints or color figure charges

- Immediate publication on acceptance

- Inclusion in PubMed, CAS, Scopus and Google Scholar

- Research which is freely available for redistribution
C) BioMed Central 